\title{
Optimized Photovoltaic Power Generator Using Artificial Neural Network Implementation for Maximum Power Point Tracking
}

\author{
N. Ghedhab and F. Youcefettoumi
}

\begin{abstract}
A photovoltaic generator present nonlinear voltage-current characteristics. A boost converter is used to match the photovoltaic system to the load charge and to operate the photovoltaic cell array at maximum power point. This paper presents an application of a neural network to identify the optimal operating point of the photovoltaic module. The power output from the modules depends on the environmental factors such as cell temperature and solar irradiation. Therefore, accurate identification of optimal operating point and continuous control of boost converter are required to achieve the maximum output efficiency. The proposed neural network has a simple structure and provides an accurate identification of the optimal operating point and also an accurate estimation of the maximum power from the photovoltaic modules. The proposed model is compared with conventional Perturb and Observe technique and shown that Artificial Neural Network can increase the overall system efficiency by approximately $10 \%$.
\end{abstract}

Index Terms-Artificial neural network (ANN), maximum power point tracking (MPPT), perturb and observe algorithm (P\&O), photovoltaic (PV) module.

\section{INTRODUCTION}

The concern of the development of alternative energy systems, which are renewable and pollution free, represent a real hope for the future. A particular role in the number of renewable energies is played by photovoltaic (PV) power generation systems. They permit an emission-free conversion of sunlight into electrical energy. The main drawbacks of PV systems is low energy-conversion efficiency which is partly caused by their nonlinear and temperature dependent $V-I$ and $P-I$ characteristics. To overcome these problems, we propose to deal with power point tracking technique (MPPT) for PV panels. There are many techniques in the literature to achieve this [1], perturb and observe $(\mathrm{P} \& \mathrm{O})$ being most common one among them [2]. But in the case of a rapid change in the solar energy flux most of the controllers fail to keep tracking the MPP. In this paper we propose using Artificial Neural Network controller (ANN), then we perform a comparison between the MPPT techniques P\&O and ANN. Simulations for both methods are carried out in Matlab / Simulink.

The paper is organized as follows. The theoretical background related to the photovoltaic power generator is reviewed in Section II. The proposed method is explained in Section III. The results from the implemented models and the

Manuscript received June 7, 2015; revised August 31, 2015.

The authors are with the Department of Electronics Engineering in University of Science and Technology Houari Boumedien, Algeria (e-mail: ghedhabnabila1@hotmail.fr, youcefettoumi@yahoo.fr).
MPPT capability of a stand-alone PV system for a battery charging application is presented and discussed in Section IV. The final conclusion is addressed in Section V.

\section{Photovoltaic Power Generator}

Solar cell is the device which absorbs the solar energy and converts it into electrical energy. These days, silicon PN junction cell which has an approximate efficiency of $17 \%$ is the most commonly used cell type. When solar radiation falls on this cell, photon creates an electron-hole pair. Typically the output of this solar cell is very low, so many of these cells are connected in series or parallel. Number of cells connected in series increases the voltage, while the number of cells connected in parallel increases the current. The circuit for the 5 parameter model given in [3] is shown in Fig. 1.

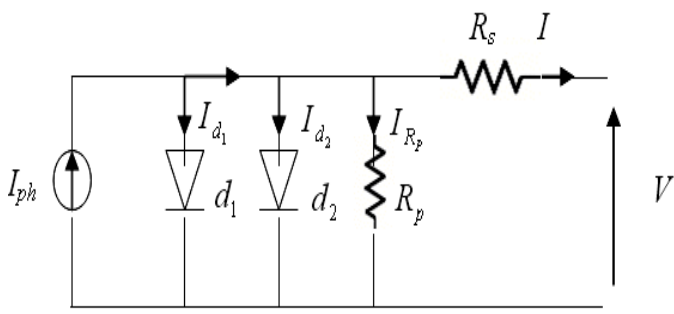

Fig. 1. Two diodes cell model.

The PV panel current is given by Equation 1. This is known as double exponential model, which offers a good compromise between simplicity and accuracy [4].

$$
I=I_{p h}-I_{s 1}\left[e^{\frac{q\left(V+I . R_{s}\right)}{n_{1} k T}}-1\right]-I_{s 2}\left[e^{\frac{q\left(V+I . R_{s}\right)}{n_{2} k T}}-1\right]-\frac{V+I R_{s}}{R_{P}}
$$

$I_{S 1}$ and $I_{S 2}$ are the saturation currents of the diodes, $n_{1}$ and $n_{2}$ are purity factors of the diodes, $R_{s}$ and $R_{p}$ are respectively the series resistance and the parallel resistance, $T$ absolute temperature in Kelvin. The equation also contains the elementary charge constant $q\left(1,602.10^{-19} \mathrm{C}\right)$ and the Boltzmann constant $k\left(1,380 \cdot 10^{-29} \mathrm{j} / \mathrm{k}\right)$. The photocurrent $I_{p h \text { max }}$ is reached at the maximum irradiation. Generally we have ( $I_{p h}=S \cdot I_{p h \text { max }}$ ) with $S$ : irradiation ratio.

The association of several PV cells in series-parallel gives rise to a photovoltaic generator (GPV), which has a current-voltage (I-V) non linear with an operating point (MPP) .This maximum power transfer happens if the internal 
resistance of the system is equal to the load resistance. This can be achieved by inserting a DC-DC converter between the load and the PV system.

The maximum power of the solar panel depends on the atmospheric conditions like ambient temperature and irradiation levels. So this maximum power has to be tracked to operate solar panel at MPP at varying conditions. In the P\&O method, power output of the array is monitored every cycle and is compared to its value before each perturbation is made. If a change (either positive or negative) in the duty cycle (D) of the DC-DC converter increases the power output, the duty cycle is changed in the same direction. If the power output decreases, then it is reversed to the opposite direction [5]. The global circuit diagram of the system adopted is shown in Fig. 2. P\&O method is simulated in Matlab / Simulink. The results for a standard atmospheric condition are shown in Fig. 3.

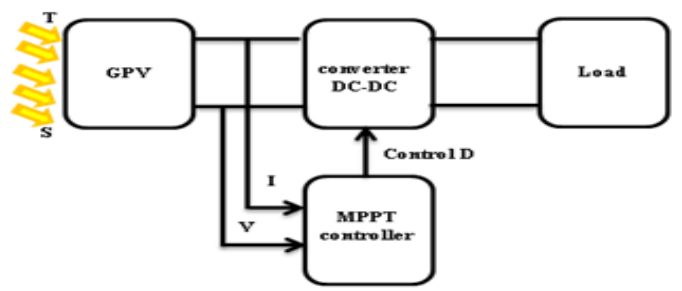

Fig. 2. Bloc diagram of an optimized photovoltaic generator using MPPT controller.
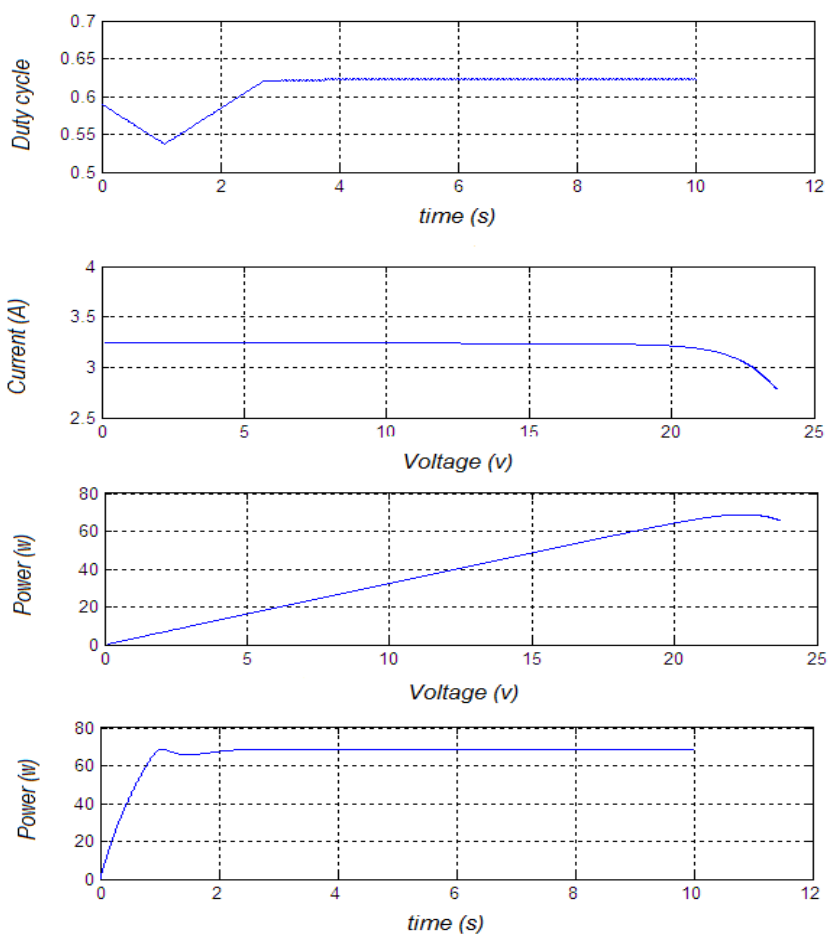

Fig. 3. MPPT simulation of the $\mathrm{P} \& \mathrm{O}$ method for the standard environmental conditions $\left(T=25^{\circ} \mathrm{C}\right.$ and $\left.S=1000 \mathrm{~W} / \mathrm{m}^{2}\right)$.

\section{The Neural Network BASED MAXIMUM Power POINT TRACKING FOR PV-SYSTEM}

A neuron is a cell made up of a cellular body and a core in which the cellular body ramifies to form the dendrites. Dendrites transfer the information between the neuron and the soma, body of the neuron. There is an intercellular space between the axon of the related neuron and dendrites of the efferent neuron. The junction between two neurons works like a valve controlling the rate of flow of information, and is called as synapse. It is necessary to parameterize all these synapses to achieve a goal. The neural network works according to the equation 2. Fig. 4 below shows the structure of an artificial neuron.

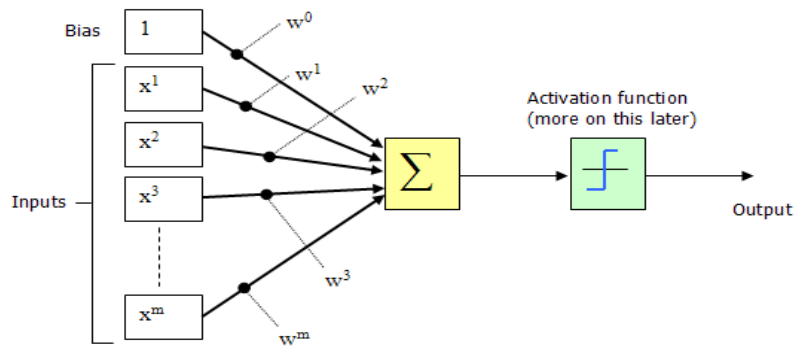

Fig. 4. Artificial neuron.

$$
a_{i}=\sum_{j=1}^{N} W_{i j} X_{j}
$$

where:

$a_{i}$ is the output of the neural network at node $i$;

$W_{i j}$ is the weight between the nodes $i$ and $j$;

$X_{j}$ are the states variables evaluated by activation functions.

\section{A. Training of Neural Networks}

The training data is obtained from the simulation of the PV array in Matlab / Simulink using the P\&O method. The current, voltage and power at MPP for a range of irradiance and ambient temperature conditions are recorded which are then used as the training data for ANN [6]. Then, the atmospheric conditions recorded are used as the input data and the target data is the value of the duty cycle $\mathrm{D}$ recorded from $\mathrm{P} \& \mathrm{O}$ method. The neural network is obtained by training in Matlab/Simulink with trainlm function using Levenberg-Marquardt algorithm [7]. During the training process the error calculation is done by algorithm of mean square error method. A goal of $1 \mathrm{e}-5$ is set with the number of failure allowed 5 times and the minimum performance of gradient of 1e-10. Training is stopped when this goal is reached.

\section{B. Description and Architecture of the Proposed Neural Network Controller}

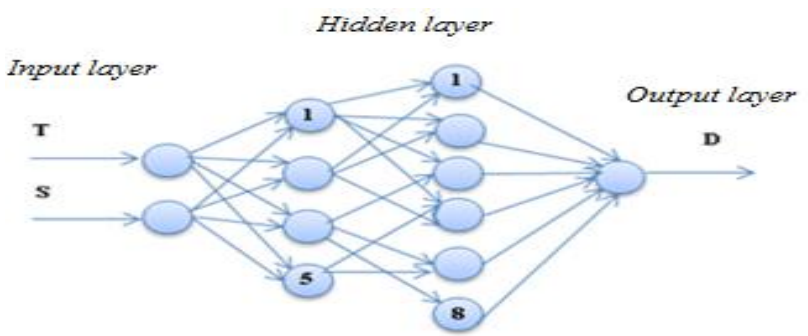

Fig. 5. The proposed neural network architecture.

The number of neurons in the hidden layer has been optimized empirically during the learning phase. Indeed, the tests have shown that the most stable structure is that composed of five neurons in first hidden layer and eight neurons for the second hidden layer. The choice of the activation function of the hidden layer for which we opted has not been adopted arbitrarily, but was chosen after several tests which showed that the function sigmoid hyperbolic converges 
faster by relative to the sigmoid tangential function during the learning phase. The neural network intended to replace the MPPT controller is selected as a static, multilayer network. As shown in Fig. 5, inputs of the ANN controller are the temperature $\mathrm{T}$ and irradiance $\mathrm{S}$, while the output is the duty cycle D.

\section{Modeling and Simulation of PV System with ANN}

The block diagram of a photovoltaic system with a neural controller MPPT in Simulink is shown in Fig. 6.

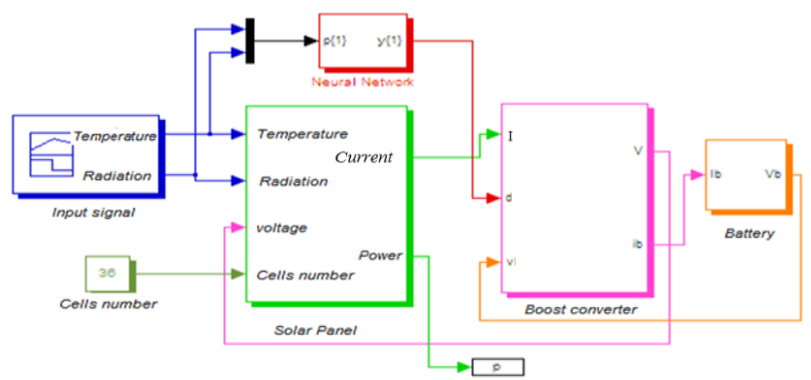

Fig. 6. Block diagram of the photovoltaic system with ANN controller in Simulink.

\section{SimUlation AND STUDY}

To verify the ability of our neural network controller, we perform the same test as applied in Fig. 2. The simulation results are shown in Fig. 7 for the standard atmospheric conditions.
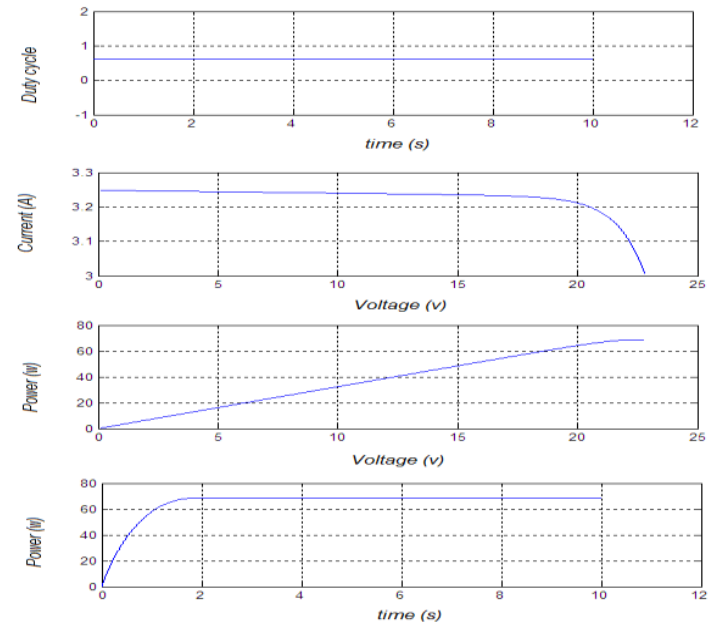

Fig. 7. Simulation for the standard condition with ANN controller $T=25^{\circ} \mathrm{C}$ and $S=1000 \mathrm{w} / \mathrm{m}^{2}$

According to the obtained result, it's shown that the ANN controller present a better performance than the MPPT P\&O one.

In order to analyze the robustness under a rapid change of atmospheric conditions we perform a simulation using the following conditions

- Solar illumination is maintained at a fixed value (1000 $\mathrm{W} / \mathrm{m}^{2}$ ) and we vary the temperature

- The temperature is kept constant $\left(T=25^{\circ} \mathrm{C}\right)$ and we vary the solar irradiance.

- We randomly vary the temperature and irradiance at the same time.

The results of the two systems are shown in a single graph, in order to compare which one is giving a better performance.
We simulate both systems under a rapid change of temperature $\left(25\right.$ and $\left.40^{\circ} \mathrm{C}\right)$ in the time interval [4], [6], as shown in Fig. 8.

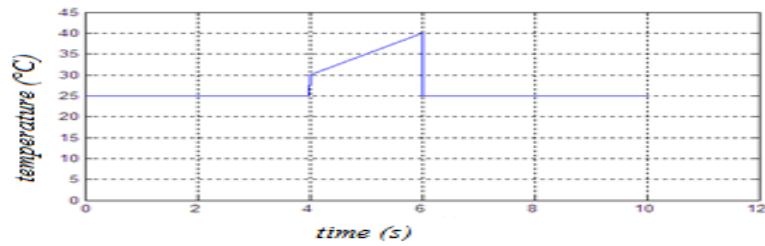

Fig. 8. Temperature between $\left(25^{\circ} \mathrm{C}-40^{\circ} \mathrm{C}\right)$.
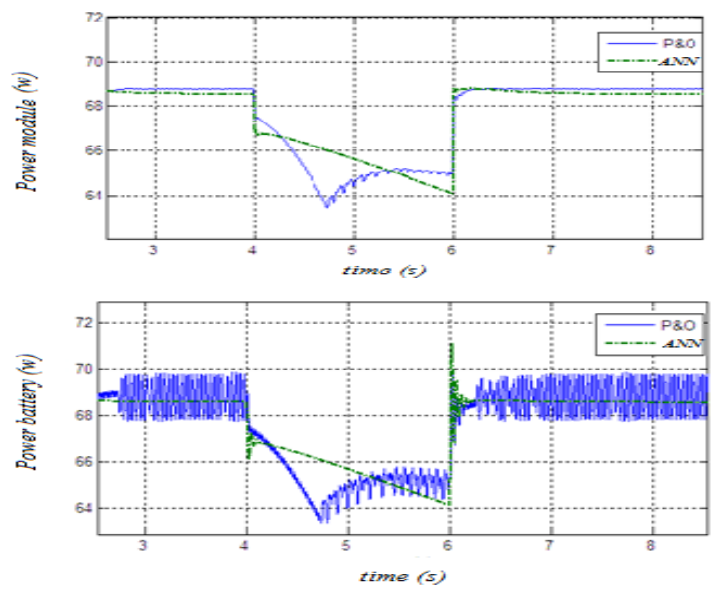

Fig. 9. Simulation $\mathrm{P} \& \mathrm{O}$ and $\mathrm{ANN}$ for $T$ variable, $\mathrm{S}$ constant.

For an increasing value of the temperature, we notice a reduction in the power output of the photovoltaic module and the power input of the battery. The results obtained show that the $\mathrm{P} \& \mathrm{O}$ controller oscillates before reaching the new MPP, while the ANN controller tends directly to this point. Those results demonstrate the ability of the ANN controller toward a rapid variation of the atmospheric conditions.

Fig. 10 illustrates the change applied in the irradiation. The simulation results are shown in Fig. 11.

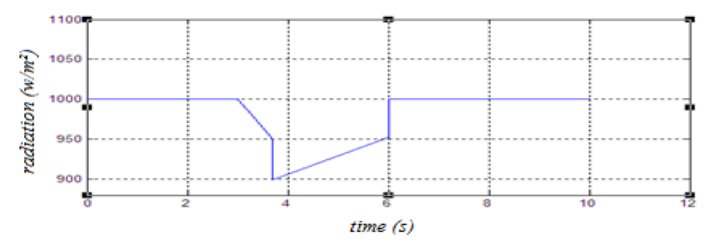

Fig. 10. Irradiation between $1000 \mathrm{w} / \mathrm{m}^{2}$ and $900 \mathrm{w} / \mathrm{m}^{2}, \mathrm{~T}=25^{\circ} \mathrm{C}$.
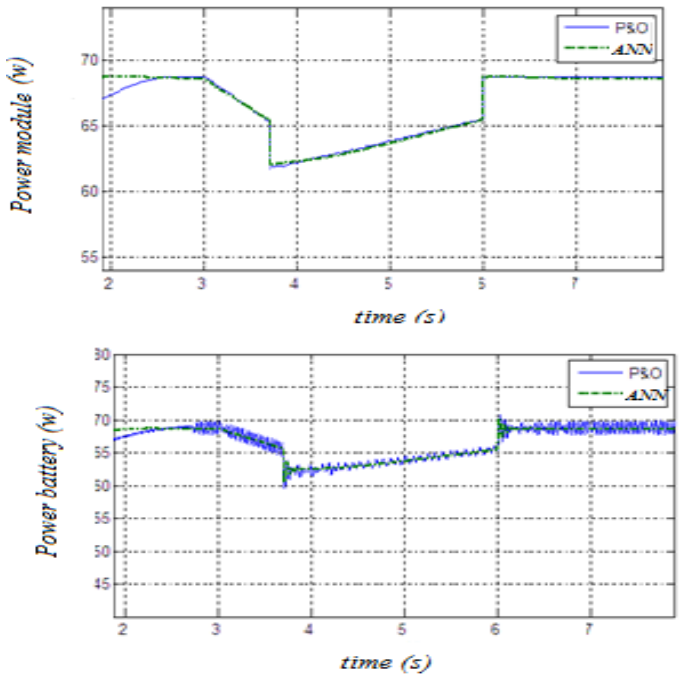

Fig. 11. Simulation $\mathrm{P} \& \mathrm{O}$ and $\mathrm{ANN}, S$ variable, T constant. 
Again, the above results (Fig. 11) show that the $\mathrm{P} \& \mathrm{O}$ controller presents oscillations around the MPP, what generate power loss that we can avoid using the ANN controller, which shows remarkable stability.

In the following simulation we analyze the photovoltaic system under a random variation of atmospheric condition, as shown in Fig. 12. The results are shown in Fig. 13.
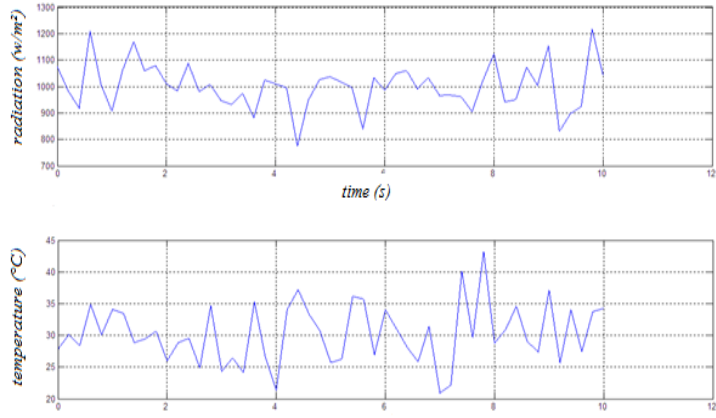

time (s)

Fig. 12. Random variation of irradiation and temperature.
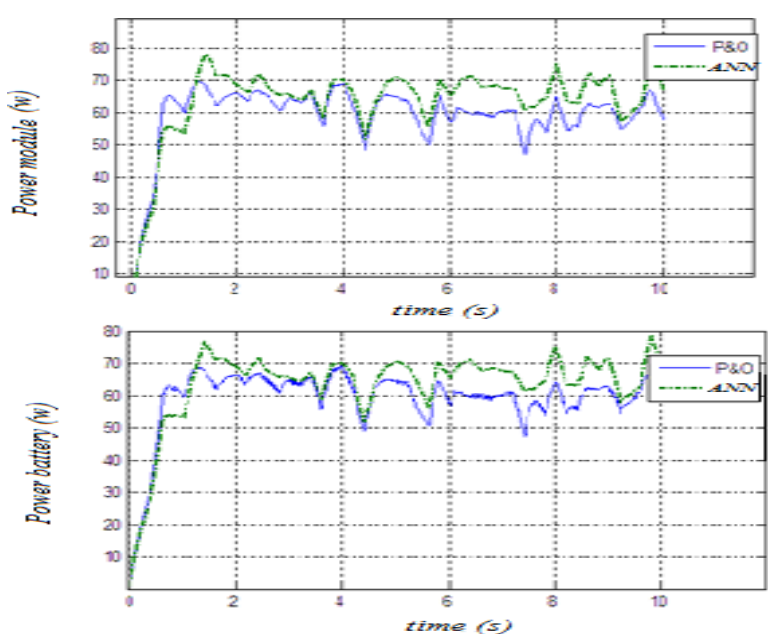

Fig. 13. Simulation $\mathrm{P} \& \mathrm{O}$ and $\mathrm{ANN}$ for a random variation of irradiation and temperature.

The results from this simulation show the good tracking of both controllers, with a higher speed and efficiency of ANN one. Fig. 14 shows the power input of the battery, obtained from each controller. We deduce that with ANN controller the overall system efficiency's increase by $10 \%$.
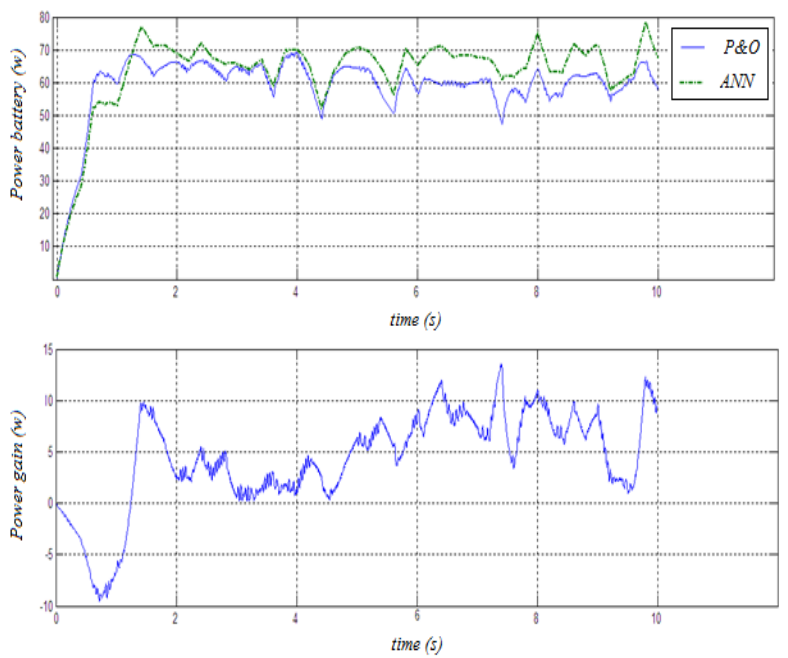

Fig. 14. Power gain from MPPT $\mathrm{P} \& \mathrm{O}$ and ANN simulation.

\section{CONCLUSION}

A Neural network based MPPT algorithm has been developed in this paper for the boost converter supplied PV systems. The proposed neural network has increased the power delivered by approximately $10 \%$. The result obtained gives accurate predictions over a wide variety of operating modes, especially for a rapid change of atmospheric conditions. The proposed method can also be a useful tool for $\mathrm{PV}$ system designers for the optimal configuration of a PV system.

\section{REFERENCES}

[1] E. T. Chapman, L. Patrick et al., "Comparison of photovoltaic array maximum power point tracking techniques," IEEE Transactions on Energy Conversion EC, vol. 22, no. 2, p. 439, June 2007.

[2] W. Xiao and W. G. Dunford, "A modified adaptive hill climbing MPPT method for photovoltaic power systems," in Proc. 35th IEEE Annual Power Electronics Specialists Conference, vol. 3, pp 1957-1963, June 2004

[3] J. A. Gow and C. Manning, "Development of a photovoltaic array model for use in power electronics simulation studies," in Proc. IEE Electric Power Applications, vol. 146, issue 2, pp. 193-200, March 1999.

[4] A. Hovinen, "Fitting of the solar cell I/V-curve to the two diode model," Physica Scripta, vol. 54, pp. 175-176, 1994.

[5] N. Femia, G. Petrone, G. Spagnuolo, and M. Vitelli, "Optimization of perturb and observe maximum power point tracking method," IEEE Transactions on Power Electronics, vol. 20, no. 4, pp. 963- 973, July 2005 .

[6] R. Ramaprabha, B. L. Mathur, and M. Sharanya, "Solar array modeling and simulation of MPPT using neural network," in Proc. International Conference on Control, Automation, Communication and Energy Conservation, INCACEC, pp. 1, 5, June 4-6, 2009.

[7] N. D. Kaushika et al., "Simulation model of ANN based maximum power point tracking controller for solar PV system," Solar Energy Materials and Solar Cells, vol. 95, no. 2, pp. 773-778, 2011.

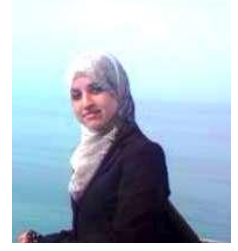

Nabila Ghedhab was born in Algiers city. She received her state engineer and her master of research degree from the Department of Electronics Engineering in University of Science and Technology Houari Boumedien, Algeria in 2006 and 2012, respectively. She is preparing her $\mathrm{PhD}$ in atmospheric radiation and she work for a national telecommunication company as a supervisor of telecom equipments. Her research areas are the autonomous radio systems, renewable energy.

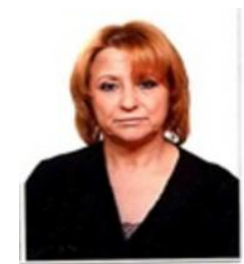

Fatiha Youcef Ettoumi was born in Algiers city received the B.S. degree, the M.S. degree and the Ph.D. from the Department of Electronics Engineering in University of Science and Technology Houari Boumedien, Algeria in 1976, 1978 and 2002, respectively. She has worked as a project manager for the Ministry of High Education, support for large schools. She is also the director of support sectora policy of higher education and scientific research program cooperation UE/DZ2009/2017.

She is a professor at University of Science and Technology Houari Boumedien, Electronics department. Actually she is the national contact point for the FP-EMS. Her research areas are the Autonomous radio systems, renewable energy. 